\title{
2-Hydroxyglutarate in Grustaceans
}

\author{
By A. K. Hugarns and A. P. Boulton \\ Department of Biochemistry, University College London, Gower Street, London WC1E 6BT, U.K.
}

(Received 4 October 1971)

It has been known for some time that a considerable proportion of the carbon from ${ }^{14} \mathrm{C}$ labelled acetate, 2-oxoglutarate or glutamate is incorporated into an unidentified compound by a number of invertebrate species, especially those of the decapod crustacean group (Huggins, Rick \& Kerkut, 1967).

The formation of this compound (designated by its identification code ' $\mathrm{U} 8$ ') occurred both in vitro and in vivo (Huggins \& Munday, 1968; Chaplin, Huggins \& Munday, 1970). Its behaviour on twodimensional paper chromatography in the isobutyric acid system of Crowley, Moses \& Ullrich (1963) and in butan-1-ol-propionic acid-water (51:26:34, by vol.) suggested that it might be a dicarboxylic acid with a greater negative charge than glutamate. No reaction could be detected with ninhydrin before or after hydrolysis in $6 \mathrm{M}$-hydro: chloric acid at $120^{\circ} \mathrm{C}$, either on chromatograms or with eluates, indicating the probable absence of an $\alpha$-amino group or an $N$-ester. Since the yield of compound U 8 was the same, allowing for the difference in the initial specific radioactivities, when crab muscle was incubated with either $\left[1-{ }^{14} \mathrm{C}\right]$ - or $\left[\mathrm{U}-{ }^{14} \mathrm{C}\right.$ ]-glutamate (for details see Huggins et al. 1967), it was concluded that decarboxylation at the 1-position had not occurred.

When supernatant extracts instead of wholetissue preparations were incubated with $\left[\mathrm{U}-{ }^{14} \mathrm{C}\right]$ glutamate, the absence of any chromatographically separable labelled compounds besides compound U 8, 2-oxoglutarate and glutamate suggested that compound $U 8$ contained a minimum of five carbon atoms. High-voltage electrophoresis in pyridineacetic acid buffer, pH 6.5 $(2000 \mathrm{~V} ; 100 \mathrm{~mA})$, showed compound $\mathrm{U} 8$ to be intermediate in mobility between succinate and glutarate. Under acid conditions ( $>1 \mathrm{~mm}$-hydrochloric acid) compound $\mathrm{U} 8$ is partially converted into another compound, which is electrophoretically and chromatographically less acidic and stable to boiling $6 \mathrm{M}$-hydrochloric acid. Elution and rechromatography of this second compound resulted in its partial reconversion into the original more acidic compound U 8, indicating a reversible interconversion between these two compounds. Neither compound U 8 nor its product on acidification were found to be chromatographically identical with any of a number of established metabolites of glutamate, including pyrrolid-2one-5-carboxylate, citramalate, mesaconate, 3methylaspartate, $N$-acetylglutamate, $N$-formiminoglutamate and pyrroline-5-carboxylate.

The increased negative charge of compound U 8 compared with glutamate could occur either by the addition of a further negatively charged group or by the removal or neutralization of the $\alpha$-amino group. Since there was no detectable reaction with reagents specific for $\alpha$-amino groups or $N$-esters of glutamate etc., possible products resulting from the deamination of glutamate were considered. 2-Oxoglutarate is the most obvious candidate, but can be excluded on both chromatographic and chemical grounds (compound U8 does not react with 2,4-dinitrophenylhydrazine). Another possibility would be the formation of 2-hydroxyglutarate by a reaction analogous to the deamination of 2-acroleyl3 -aminofumarate to $\alpha$-hydroxymuconic $\delta$-semialdehyde (Gholson et al. 1962). 2-Hydroxyglutarate could also be formed from the 2-oxoglutarate present by an oxidoreductase enzyme of the type described by Reitz \& Rodwell (1969) in Pseudomonas putida, rather than by a direct deamination of glutamate.

Two-dimensional paper co-chromatography of radioactive compound U8 with authentic 2hydroxyglutaric acid (Sigma Chemical Co., St Louis, Mo., U.S.A.) gave excellent superimposition of the radioactive area detected radioautographically, with the carrier 2-hydroxyglutarate detected by reaction with Methyl Red.

The identity of compound U 8 with 2-hydroxyglutarate was then confirmed by silicic acid column chromatography. The radioactive compound U 8 spots from the two-dimensional paper chromatograms were removed and eluted with water, $100 \mu$ equiv. of 2-hydroxyglutarate was added as a carrier and the water was removed in vacuo at $40^{\circ} \mathrm{C}$. The residue was dissolved in $1.0 \mathrm{ml}$ of $0.5 \mathrm{M}$ sulphuric acid and mixed intimately with $2 \mathrm{~g}$ of silicic acid before being applied to a silicic acid column $(15 \mathrm{~cm} \times 1.5 \mathrm{~cm})$ prepared by the method of Bové \& Raveux (1957). The radioactivity was eluted by a stepwise gradient of 2-methylpropan2-ol in washed chloroform (see Fig. 1). Fractions of volume $2.5 \mathrm{ml}$ were collected, $0.05 \mathrm{ml}$ of each fraction was placed in a scintillation vial with $10 \mathrm{ml}$ of toluene 


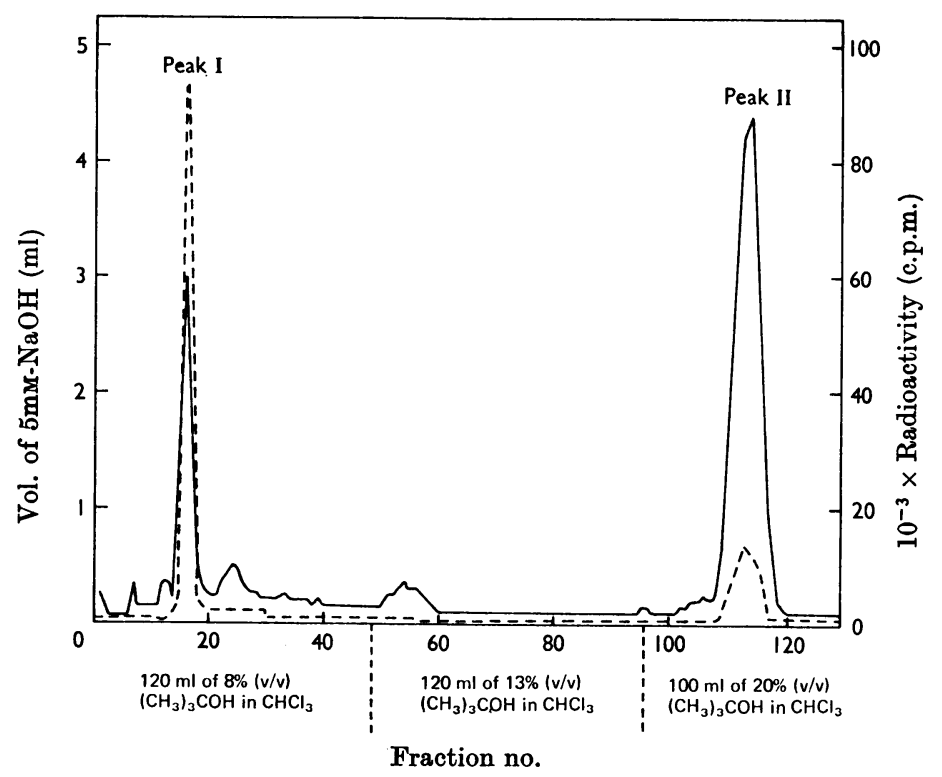

Fig. 1. Silicic acid co-chromatography of compound U8 eluted from radiochromatograms and authentic 2-hydroxyglutaric acid. The fractions were analysed for both radioactivity (-....) and acidity ( - ). Of the two major peaks, peak I gives a positive test for lactones and peak II is free 2-hydroxyglutaric acid.

containing $\quad 0.6 \% \quad 2,5$-bis-(5-tert.-butylbenzoxazol2-yl)thiophen (BBOT), and the radioactivity present in each fraction was determined in a Beckman scintillation counter. The remainder of each fraction was titrated against $5 \mathrm{~mm}$-sodium hydroxide to determine the amount of acid present.

As shown in Fig. 1 two main peaks I and II were present in which the radioactivity and acidity were coincident. The elution characteristics of these peaks indicated that peak II corresponded to 2 hydroxyglutaric acid. Hydroxy acids tend to lactonize (Dalgliesh, Johnson, Long \& Tyler, 1952), and material from peak I gave a positive reaction for lactones (Fiegel, 1960) and was shown to be chromatographically identical with 2-hydroxyglutaric acid lactone (prepared from 2-hydroxyglutaric acid by the method of Bleiweis, Reeves \& Ajl, 1967) on two-dimensional paper chromatography [ $R_{F} 0.46$ in solvent 1 and $R_{F} 0.45$ in solvent 2 (Crowley et al. 1963)] and ascending silica-gel t.l.c. [ $R_{F} 0.59$ in butan-1-ol-acetic acid-water (12:3:50, by vol.) and $R_{F} 0.45$ in benzene-methanol-acetic acid (45:8:4, by vol.)]. In each case approx. 2000c.p.m. was applied to the plates or paper together with $50 \mu \mathrm{g}$ of authentic lactone. The separated radioactive areas on the paper chromatograms were then detected by radioautography, and the acid areas on the papers were located by dipping in Bromocresol Green $\mathbf{( 0 . 0 5 \%}$ in ethanol). The radioactivity was found to be coincident with the acidic areas. After development of the t.l.c. plates the acidic areas were located with Bromocresol Green and scraped off into scintillation vials containing $2 \mathrm{~g}$ of Cab-O-Sil, $10 \mathrm{ml}$ of toluene-2,5-bis(5-tert.-butylbenzoxazol-2-yl)thiophen mixture was then added and the radioactivity was measured in a Beckman scintillation counter. In every case over $98 \%$ of the added radioactivity was recovered with the marker lactone added.

Peak II material was similarly treated. After paper chromatography two radioactive areas were found, corresponding to 2-hydroxyglutaric acid and its lactone. Presumably the acidic solvents used caused some lactonization, and in view of this peak II was subjected to silica-gel t.l.c. in an alkaline solvent [ethanol-aq. ammonia (sp.gr. 0.88)-water (18:1:1, by vol.)], giving $R_{F} 0.35$. Over $98 \%$ of the added radioactivity was recovered with the 2-hydroxyglutaric acid marker. Peak II material was then converted into the lactone by the method of Bleiweis et al. (1967), and behaved exactly as authentic lactone under the procedures used for peak I.

These results show the identity of compound U 8 to be 2-hydroxyglutarate. Measurements of the tissue content are complicated by the lactonization that results from the analytical procedures omployed, but we have obtained a value (including 
lactone) for 2-hydroxyglutarate in Cancer pagurus leg muscle of approx. $240 \mu \mathrm{mol} / \mathrm{kg}$ wet wt. of muscle.

In Escherichia coli (Reeves \& Ajl, 1962; Reeves, Stahl \& Ajl, 1963) and Aspergillus glaucus (Bleiweis et al. 1967) 2-hydroxyglutarate is produced by the condensation of propionyl-CoA with glyoxylate. It is also implicated in the metabolism of 2-amino-5hydroxyadipate in the rat (Lindahl, Lindstedt \& Lindstedt, 1967) and of L-pipecolate in Pseudomonas putida (Reitz \& Rodwell, 1969), but we are not aware of any previous report of the occurrence of 2-hydroxyglutarate in the invertebrate phyla. We have detected a crab mitochondrial enzyme that catalyses the dehydrogenation of 2-hydroxy glutarate to 2-oxoglutarate. The absence of labelled products from glutamate other than 2-oxoglutarate suggests that 2-hydroxyglutarate formation may occur by transamination or dehydrogenation of glutamate to produce 2-oxoglutarate, which could then undergo reduction.

We are indebted to the Science Research Council for financial support, and to Mrs W. C. Rowe and Mr M. Schachter for assistance at various stages of the investigation.
Bleiweis, A. S., Reeves, H. C. \& Ajl, S. J. (1967). J. Bact. 94, 1560.

Bové, J. \& Raveux, R. (1957). Bull. Soc. chim. Fr. p. 376.

Chaplin, A. E., Huggins, A. K. \& Munday, K. A. (1970). Int. J. Biochem. 1, 385.

Crowley, G. J., Moses, V. \& Ullrich, J. (1963). J. Chromat. $12,219$.

Dalgliesh, C. E., Johnson, A. W., Long, A. G. \& Tyler, G. J. (1952). In Chemistry of Carbon Compounds, vol. 1, p. 1114. Ed. by Rodd, E. M. Amsterdam: Elsevier Publishing Co.

Fiegel, F. (1960). Spot Tests in Organic Analysis, 6th ed., p. 250. Amsterdam: Elsevier Publishing Co.

Gholson, R. L., Nishizuka, Y., Ichiyama, A., Kawai, H., Nakamura, S. \& Hayaishi, O. (1962). J. biol. Chem. 237, Po 2043.

Huggins, A. K. \& Munday, K. A. (1968). Adv. comp. Physiol. Biochem. 3, 271.

Huggins, A. K., Rick, J. T. \& Kerkut, G. A. (1967). Comp. Biochem. Physiol. 21, 23.

Lindahl, G., Lindstedt, G. \& Lindstedt, S. (1967). Archs Biochem. Biophys. 119, 347.

Reeves, H. C. \& Ajl, S. J. (1962). J. Bact. 84, 186.

Reeves, H. C., Stahl, W. J. \& Ajl, S. J. (1963). J. Bact. 86, 1352.

Reitz, M. S. \& Rodwell, V. W. (1969). J. Bact. 100, 708. 